Research Paper

\title{
Effects of Remifentanil Preconditioning on Osteoblasts under Hypoxia-Reoxygenation Condition
}

\author{
Seung-Wan Baik¹, Bong-Soo Park², Yong-Ho Kim², Yong-Deok Kim³ , Cheul-Hong Kim4, Ji-Young Yoon, \\ Ji-Uk Yoon ${ }^{\circledR}$ \\ 1. Department of Anesthesia and Pain Medicine, School of Medicine, Pusan National University, Gyeongnam, Korea \\ 2. Department of Oral Anatomy, School of Dentistry, Pusan National University, Gyeongnam, Korea \\ 3. Department of Oral and Maxillofacial Surgery, School of Dentistry, Pusan National University, Gyeongnam, Korea \\ 4. Department of Dental Anesthesia and Pain Medicine, School of Dentistry, Pusan National University, Gyeongnam, Korea
}

$\triangle$ Corresponding author: Ji-Uk Yoon, M.D., Ph.D., Department of Anesthesia and Pain Medicine, School of Medicine, Pusan National University, Mulgeum-eup, Yangsan-si, Gyeongnam 626-770, Korea. Telephone Number: +82-55-360-2129; FAX Number: +82-55-360-2149; E-mail Address: jiuk@pusan.ac.kr

(c) 2015 Ivyspring International Publisher. Reproduction is permitted for personal, noncommercial use, provided that the article is in whole, unmodified, and properly cited. See http://ivyspring.com/terms for terms and conditions.

Received: 2015.02.10; Accepted: 2015.06.09; Published: 2015.07.15

\begin{abstract}
Background: Ischemia-reperfusion of bone occurs in a variety of clinical conditions, such as orthopedic arthroplasty, plastic gnathoplasty, spinal surgery, and amputation. Usually, cellular models of hypoxia-reoxygenation reflect in vivo models of ischemia-reperfusion. With respect to hypoxia-reoxygenation conditions, the effects of remifentanil on osteogenesis have received little attention. Therefore, we investigated the effects of remifentanil on the proliferation and differentiation of osteoblasts during hypoxic-reoxygenation.

Methods: After remifentanil $(0.1,1 \mathrm{ng} / \mathrm{mL})$ preconditioning for 2 hours, human osteoblasts were cultured under $1 \%$ oxygen tension for 24 hours. Thereafter, the cells were reoxygenated for 12 hours at $37{ }^{\circ} \mathrm{C}$. The naloxone groups were treated with naloxone for 30 minutes before remifentanil treatment. We measured cell viability via MTT assay. Osteoblast maturation was determined by assay of bone nodular mineralization. Quantitative PCR and western blot methods were used to determine BMP-2, osteocalcin, Akt, type I collagen, osterix, TGF- $\beta 1$, HIF-1 $\alpha$, and RUNX2 expression levels.

Results: Osteoblast viability and bone nodular mineralization by osteoblasts is recovered by remifentanil preconditioning from hypoxia-reoxygenation insult. During hypoxic-reoxygenation condition, remifentanil preconditioning induced the expression of BMP-2, osteocalcin, Akt, type I collagen, osterix, TGF- $\beta 1$, HIF-1 $\alpha$, and RUNX2 in osteoblasts.

Conclusions: Under hypoxia-reoxygenation conditions, remifentanil preconditioning enhanced the cell viability and maturation of osteoblasts, and stimulated the expression of proteins associated with osteoblast proliferation and differentiation of the osteoblast. Our results suggest that remifentanil may help in the treatment of bone stress injuries.
\end{abstract}

Key words: remifentanil, hypoxia-reoxygenation, osteoblast

\section{Introduction}

Bone ischemia-reperfusion is encountered in various clinical settings, such as orthopedic arthroplasty, plastic gnathoplasty, spinal surgery, and amputation. In general, hypoxia-reoxygenation injury, which occurs in a variety of clinical conditions, is important in human pathophysiology. Well-known clinical problems that lead to cellular injury during hypoxia-reoxygenation include circulatory shock, myocardial ischemia, cerebral stroke, and transplantation of organs [1, 2, 3]. Previous research using in vitro models of hypoxia-reoxygenation injury has provided useful clues for studying the mechanisms of 
cellular dysfunction in human organs during ischemia-reperfusion [4].

When bone fracture occurs, the blood supply to tissue is reduced or disrupted, and neovascularization and vascular growth occur during fracture healing. This process may be thought to involve a reperfusion event of a relatively ischemic area and generation of oxygen free radicals. The protective effect on limb ischemia-reperfusion injury induced by oxygen free radical scavengers supports this suggestion [5]. In addition, it has been reported that osteoblast-like cells produce measurable amounts of superoxide and hydrogen peroxide radicals during hypoxia-reoxygenation [6].

Remifentanil, an ultra-short-acting mu-opioid receptor agonist, is unique from other opioids because of its esterase-based metabolism, minimal accumulation, and very rapid onset and offset of clinical action. Remifentanil can prevent inflammatory response and can suppress inducible nitric oxide synthase expression in a septic mouse model [7]. After cardiopulmonary bypass for coronary artery surgery, remifentanil can also inhibit the release of biomarkers of myocardial damage [8]. However, the effects of remifentanil on osteoblasts during hypoxia-reoxygenation have received little direct attention. The objective of our study was to determine whether remifentanil has a protective effect against hypoxia-reoxygenation in osteoblast and, if so, whether factors associated with the proliferation and differentiation of osteoblasts mediate this effect.

\section{Materials and methods}

\section{Cell Culture and Drug Treatment}

A human osteoblast cell line, hFOB 1.19, was obtained from the American Type Culture Collection (Rockville, MD, USA). This cell line was maintained at $37{ }^{\circ} \mathrm{C}$ with an atmosphere of $5 \% \mathrm{CO}_{2}$ in air, in
DMEM/F-12 medium with $4 \mathrm{mM}$ L-glutamine, 1.5 $\mu \mathrm{g} / \mathrm{L}$ sodium bicarbonate, $4.5 \mathrm{~g} / \mathrm{L}$ glucose and 1.0 $\mathrm{mM}$ sodium pyruvate, supplemented with $10 \%$ fetal bovine serum (FBS).

To determine whether the administration of remifentanil (Ultiva; GlaxoSmithKline Pharmaceuticals, Uxbridge, UK) affects osteoblast hypoxia-reoxygenation injury, cells were randomly assigned to receive different concentrations $(0.1,1 \mathrm{ng} / \mathrm{mL})$ of remifentanil pretreatment for 2 hours before hypoxia-reoxygenation. A control group did not receive the pretreatment. The normoxia group was not subjected to hypoxia and the naloxone (NLX) group was treated with naloxone for 30 minutes before the remifentanil treatment.

\section{Hypoxia of cultured osteoblasts}

Osteoblasts were cultured under 1\% oxygen tension. Cells were seeded in 96-well plates at $1 \times 10^{4}$ cells per well, before exposure to hypoxia. Cells were incubated in an atmosphere of $94 \% \mathrm{~N}_{2}$ and $5 \% \mathrm{CO}_{2}$ using a ProOx 110 compact oxygen controller (BioSpherix, USA) at $37^{\circ} \mathrm{C}$ for 24 hours. To simulate reoxygenation and recovery, the cells were reoxygenated for 12 hours at $37^{\circ} \mathrm{C}$ (Fig. 1).

\section{Assay of cell viability}

Cells were cultured in a 96-well plate and incubated for 36 hours. One hundred microliters of colorimetric 3-(4,5-dimethylthiazol-2-yl)-2,5-diphenyltetrazolium bromide (MTT: $0.5 \mathrm{mg} / \mathrm{mL}$ final concentration) was added and incubated in the dark for an additional 4 hours at $37^{\circ} \mathrm{C}$ to induce the production of formazan crystals. The medium was aspirated and any formazan crystals that had formed were dissolved in DMSO. Cell viability was monitored on a Sunrise Remote Control ELISA reader (Tecan Group Ltd., Männedorf, Switzerland) at an excitatory emission wavelength of $570 \mathrm{~nm}$.

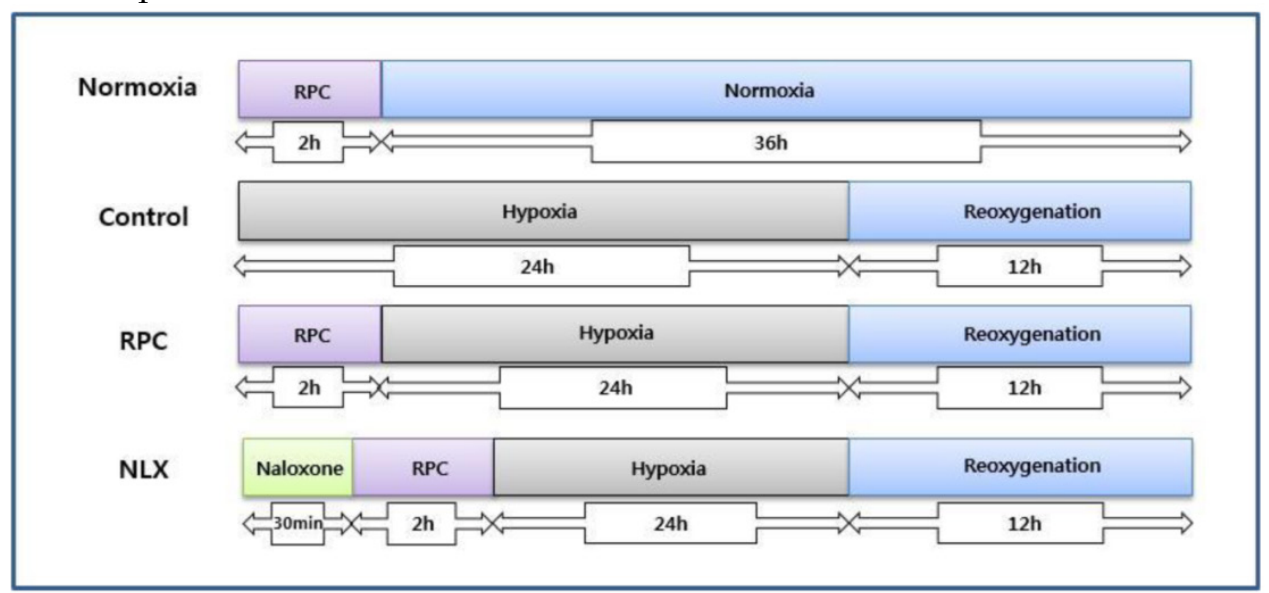

Figure 1. The experimental protocols followed for all in vitro experiments are represented as follows. Normoxia $=$ normoxia group: Control = group not treated with remifentanil: RPC = remifentanil preconditioning group: NLX = group treated with both naloxone and remifentanil. 


\section{Assay of osteoblast bone nodular mineralization}

Osteoblast maturation was determined by evaluating cell mineralization using the alizarin red $S$ dye staining. Osteoblasts were seeded in $6 \mathrm{~cm}$ tissue culture dishes coated with chitosan nanofiber scaffolds, and were treated with a combination of $10 \mathrm{nM}$ dexamethasone, $100 \mu \mathrm{g} / \mathrm{mL}$ ascorbic acid, and $10 \mathrm{mM}$ $\beta$-glycerophosphate for 21 days. After drug treatment, osteoblasts were washed with ice-cold PBS and then fixed in ice-cold $10 \%$ formalin for 20 minutes. Cells were washed with PBS and photographed using phase-contrast microscopy. The reaction was stopped by washing cells twice with deionized water. For the alizarin red S dye protocol, fixed osteoblasts were thoroughly rinsed and then incubated in 1\% Alcian blue $\mathrm{pH} 2.5$ (Thermo Fisher Scientific) for 12 hours. Sections were then incubated in alizarin red $S$ (Thermo Fisher Scientific) for 8 minutes, dehydrated briefly in xylene, and covered with a coverslip in Permount (Thermo Fisher Scientific). Mineralized nodules were visualized and counted using an inverted microscope. Each experiment was performed in duplicate wells and repeated three times.

\section{Quantitative reverse transcriptional PCR}

Total RNA was extracted from the hFOB cells using Trizol reagent (Thermo Fisher Scientific, Waltham, MA, USA) according to the manufacturer's instructions. Total RNA $(2 \mu \mathrm{g})$ was reverse transcribed using a RevertAid ${ }^{\mathrm{TM}}$ First Strand cDNA synthesis kit (Thermo, Fremont, CA, USA) according to the manufacturer's protocol. Real-time PCR was performed on an Applied Biosystems 7500 Fast Real-Time PCR System with the 7500 System Sequence Detection System (SDS) v. 2.0.1 software (Thermo Fisher Scientific), and using SYBR Green PCR Master Mix (Thermo Fisher Scientific). Primers for BMP-2 (forward: 5'-ACC AGG TTG GTG AAT CAG AA-3' and reverse: 5'-TTT GGC TTG ACG TTT TTC TC -3'), osteocalcin (forward: 5'- ATG AGA GCC CTC ACA CTC CT-3' and reverse: 5'- GGA TTG AGC TCA CAC ACC TC-3') Akt (forward: 5'-TTT GCA AAA TGG AGG AGG AA and reverse: 5'-TCA AAC AAA CGA GCA GTG CA-3'), type I collagen (forward: 5'-CGT GGT GTA ACT GGT CCT TC-3' and reverse: 5'-ACC GGG CTC TCC CTT ATC -3'), osterix (forward: 5'-CCC TCC CTT TTC CCA CTC AT-3' and reverse: 5'-TGG AGT AGG AGT GTT GCC TG-3'), TGF- $\beta 1$ (forward: 5'-TCT TTT GAT GTC ACC GGA GT-3' and reverse: 5'-CGT GGA GCT GAA GCA ATA GT -3'), HIF-1a (forward 5'-GAT TCA AGT GGT CTT CCT GCT TCA GC-3' and reverse 5'-GGG ACT CAT CCC AGG CGG G-3') and RUNX2 (forward: 5'-CTG TGG TTA CTG TCA TGG CG-3' and reverse: 5'-AGG TAG CTA CTT
GGG GAG GA-3')were used, with GAPDH (forward: 5'-GGAAGG ACT CAT GAC CAC AG-3' and reverse: 5'-TTGGCAGGTTTTTCT AGA CG-3') as an internal control. The conditions for the PCR were as follows: $50{ }^{\circ} \mathrm{C}$ for 2 minutes, $95^{\circ} \mathrm{C}$ for 10 minutes and 40 cycles of $95^{\circ} \mathrm{C}$ for 15 seconds, $60^{\circ} \mathrm{C}$ for 1 minute and $72{ }^{\circ} \mathrm{C}$ for 30 seconds. Real-time PCR data were analyzed using SDS version 2.0.1 (Thermo Fisher Scientific).

\section{Western blot assay}

Cells were plated at a density of $1 \times 10^{5}$ cells in 6-well plates. Cells were washed twice with ice-cold PBS and centrifuged at $2000 \mathrm{rpm}$ for 10 minutes. Total cell proteins were lysed with a RIPA buffer [300 mM $\mathrm{NaCl}, 50 \mathrm{mM}$ Tris-HCl (pH 7.6), 0.5\% TritonX-100, 2 $\mathrm{mM}$ PMSF, $2 \mu \mathrm{g} / \mathrm{mL}$ aprotinin, and $2 \mu \mathrm{g} / \mathrm{mL}$ leupeptin] and incubated at $4{ }^{\circ} \mathrm{C}$ for 1 hour.

The lysates were centrifuged at $14000 \mathrm{rpm}$ for 15 minutes at $4{ }^{\circ} \mathrm{C}$, and sodium dodecyl sulfate (SDS) and sodium deoxycholic acid $(0.2 \%$ final concentration) were added. Protein concentrations of cell lysates were determined with a Bradford protein assay kit (Bio-Rad, Richmond, CA, USA) using BSA as a protein standard. A sample of $50-\mu$ g protein from each well was separated and electrophoresed by 7.5-10\% SDS-PAGE. The gels were transferred to nitrocellulose membrane (Amersham Pharmacia Biotech, Piscataway, UK) and treated with each antibody. Immunostaining with the antibodies was performed using Super Signal West Pico enhanced chemiluminescence substrate and detected with an Alpha Imager HP (Alpha Innotech, San Leandro, USA). Equivalent protein loading was confirmed by Ponceau $S$ staining.

\section{Statistical methods}

Experiments were repeated five times. Multiple groups were compared using one-way analysis of variance (ANOVA) followed by post-hoc Tukey's test, using SPSS 13.0 (IBM Corp., Armonk, NY, USA). The data were expressed as the mean \pm standard deviation (SD). Values of $\mathrm{P}<0.05$ were considered significant.

\section{Results}

\section{Effect of remifentanil preconditioning on cell proliferation}

The cell viability assay was performed 36 hours after treatment with remifentanil. The cell proliferation rate (\%) was calculated and compared with the non-treatment group of normoxia groups. The control group had lower cell viability than the non-treatment group of normoxia groups. Remifentanil preconditioning had no influence on cell viability of the normoxia groups (Fig. 2A). In remifentanil preconditioning (RPC) groups, the cell viability was higher in 
the 0.1 and $1 \mathrm{ng} / \mathrm{mL}$ groups compared to the control group $(\mathrm{P}<0.05$ : Fig. $2 \mathrm{~B})$. The results of the NLX groups were similar to those of the RPC groups (Fig. $2 \mathrm{C})$. The cell viability was greatest at a remifentanil concentration of $1 \mathrm{ng} / \mathrm{mL}$

\section{Effect of remifentanil preconditioning on bone nodular mineralization}

Abundant bone nodular mineralization occurred in normoxia groups, and remifentanil preconditioning
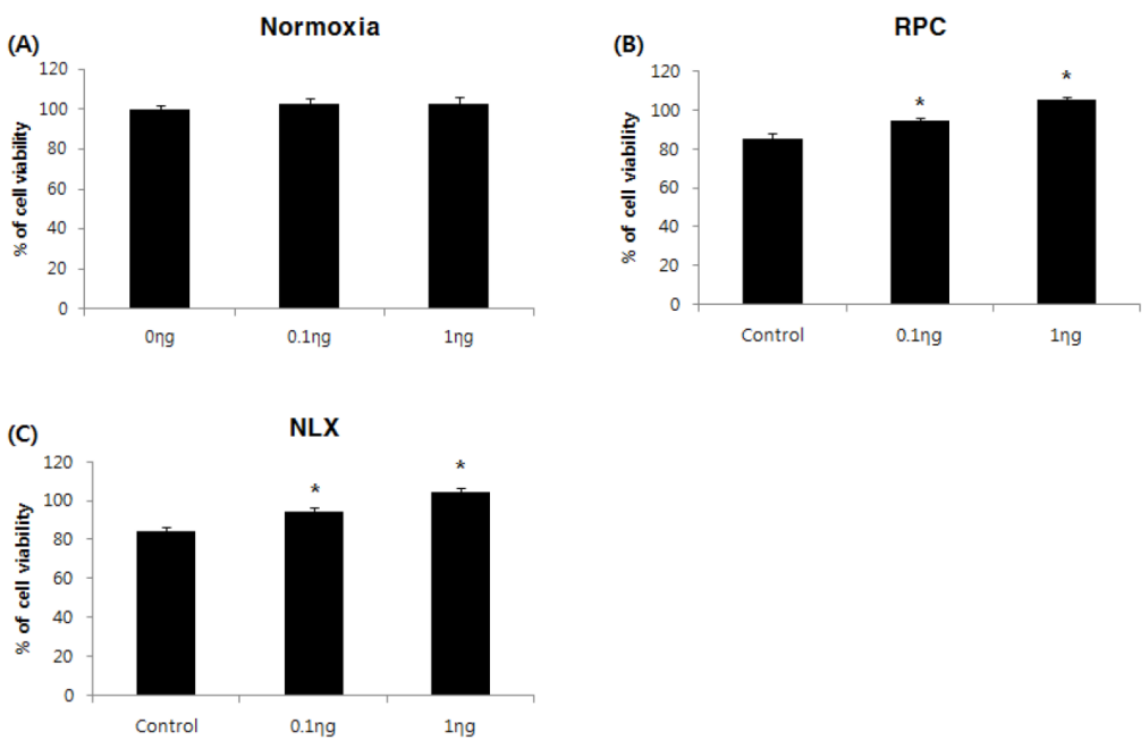

had no influence on normoxia groups. RPC groups showed higher bone nodular mineralization compared to the control group and bone nodular mineralization increased gradually with increasing remifentanil preconditioning. Similar results were found in the NLX groups (Fig. 3).

Figure 2. Effects of remifentanil treatment on hFOB cell viability assessed by MTT assay. (A) Effect of remifentanil treatment on cell viability under normoxia. (B) Effect of remifentanil treatment on cell viability under hypoxia-reoxygenation. (C) Effect of naloxone and remifentanil treatment on cell viability under hypoxia-reoxygenation. $* P<0.05$ compared with control group.

(A)

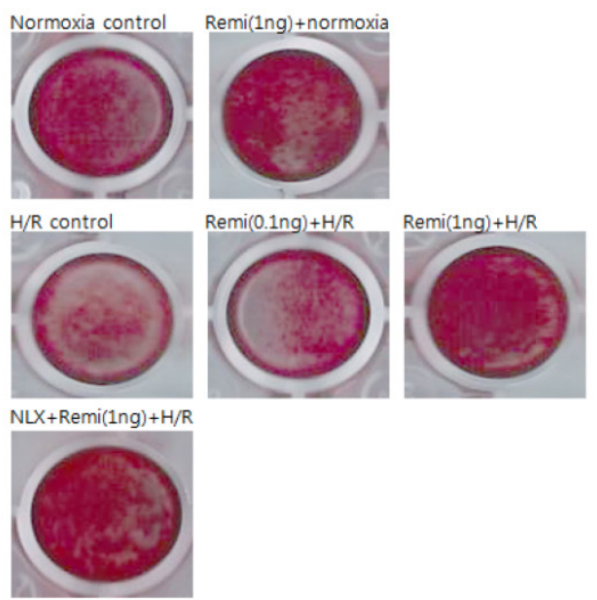

(B)

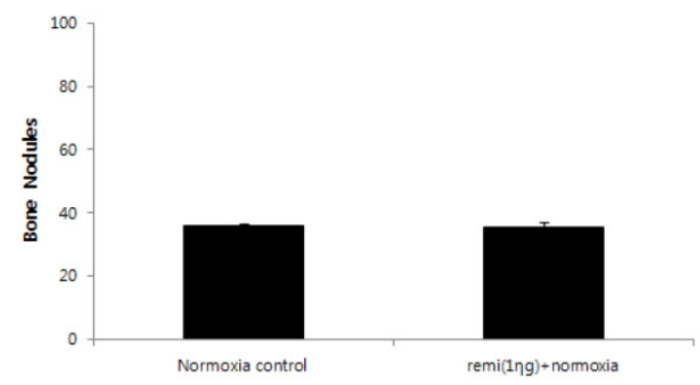

(C)

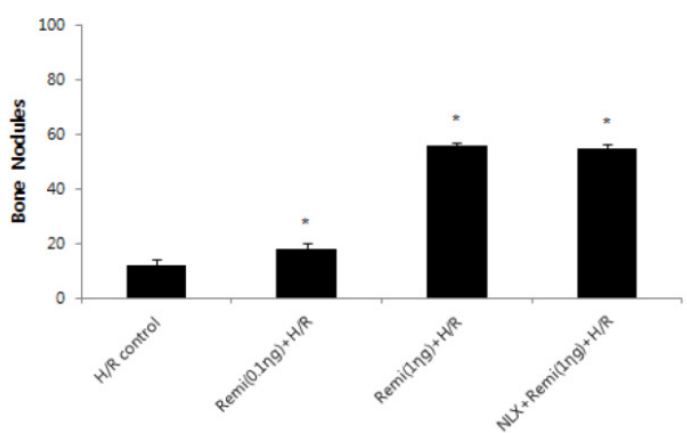

Figure 3. Bone nodular mineralization assay. (A) Representative images of bone nodules after 21 days of staining in alizarin red $S$ dye. (B \& C) Quantified bone nodular mineralization using image analysis software. $* \mathrm{P}<0.05$ compared with the control group. 


\section{Effect of remifentanil preconditioning on BMP-2, osteocalcin, Akt, type I collagen, osterix, TGF- $\beta 1$, HIF- $1 \alpha$, and RUNX2}

The expressions of BMP-2, osteocalcin, Akt, type I collagen, osterix, TGF- $\beta 1$, HIF- $1 \alpha$, and RUNX2m RNAs were markedly increased in the 0.1 and 1 $\mathrm{ng} / \mathrm{mL}$ groups compared to the control group, and the peak expression of mRNAs were observed when cells were treated with $1 \mathrm{ng} / \mathrm{mL}$ remifentanil (Fig. 4). In the western blot analysis, similar to the results of PCR, remifentanil preconditioning was found to increase the expression of BMP-2, osteocalcin, Akt, type I collagen, osterix, TGF- $\beta 1$, HIF- $1 \alpha$, and RUNX2 (Fig. $5)$. These results suggest that pretreatment with remifentanil induces the expression of BMP-2, osteocalcin, Akt, type I collagen, osterix, TGF- $\beta 1, \mathrm{HIF}-1 \mathrm{a}$, and RUNX2 in osteoblasts under hypoxic-reoxygenation.
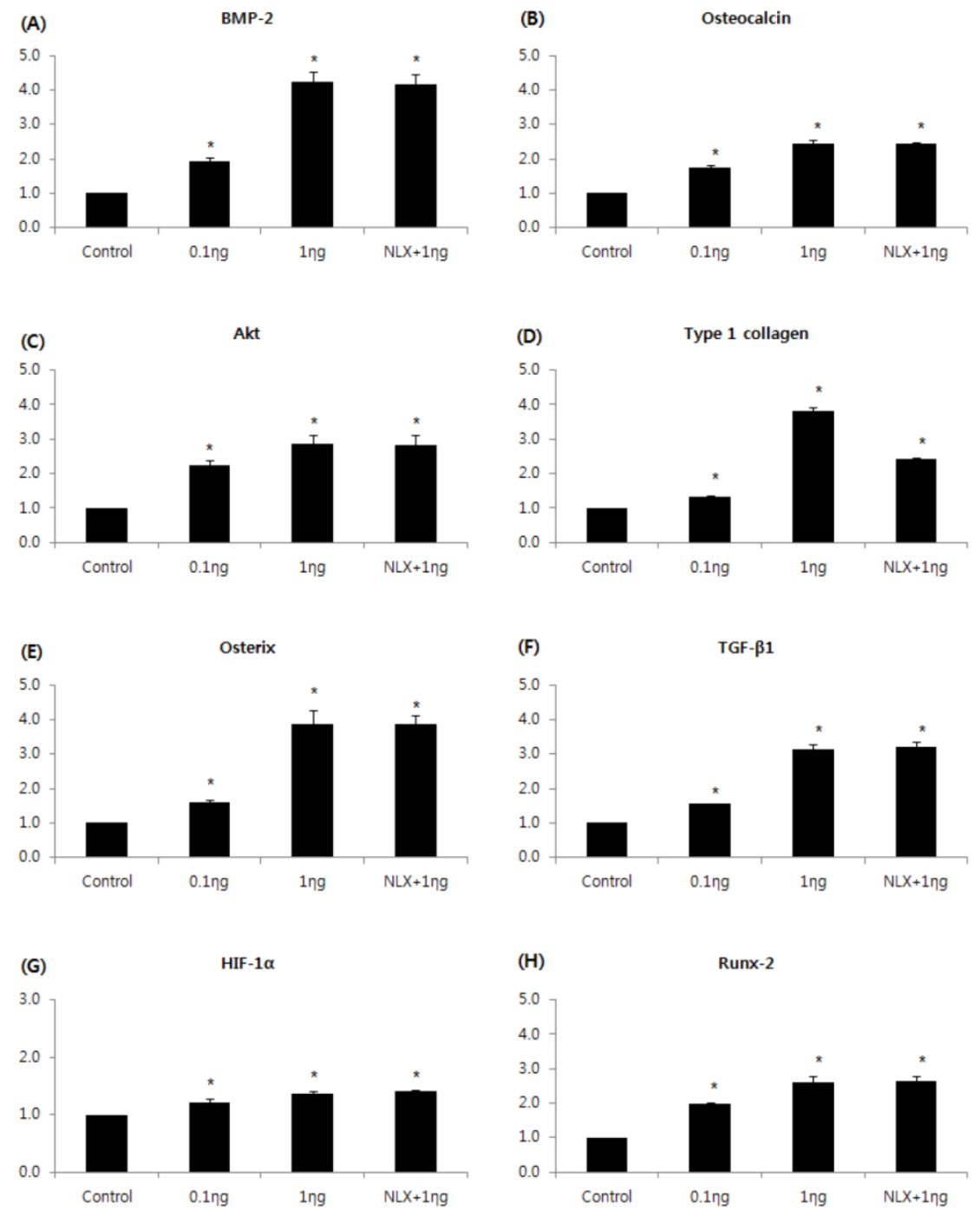

Figure 4. Effects of remifentanil treatment on the expression of BMP-2 (A), osteocalcin (B), Akt (C), type I collagen (D), osterix (E), TGF- $\beta 1$ (F), HIF-1a $(\mathrm{G}), \mathrm{RUNX}-2(\mathrm{H})$ in hFOB cells under hypoxia-reoxygenation. *P $<0.05$ compared with the control group. 

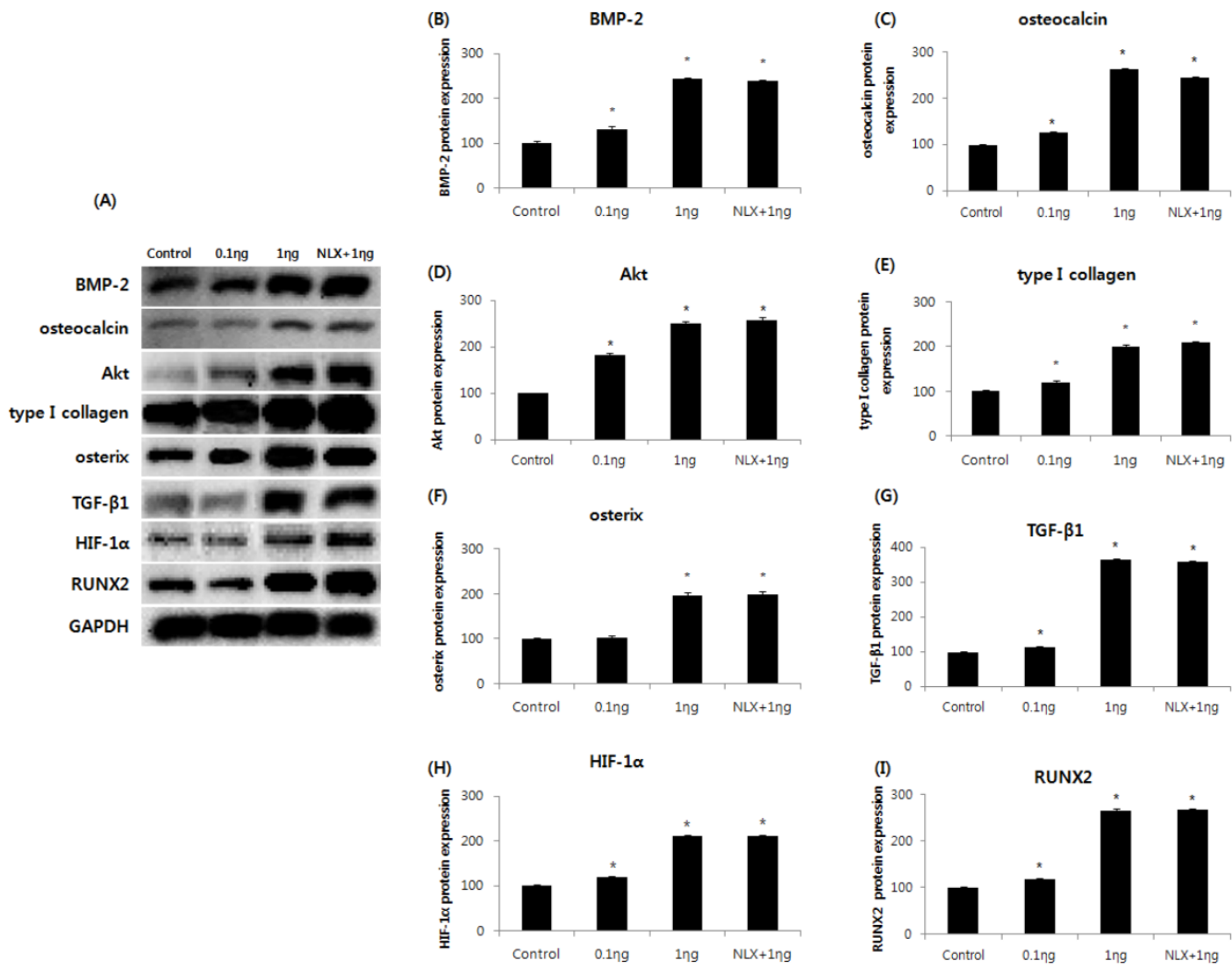

Figure 5. Effects of remifentanil treatment on BMP-2 (B), osteocalcin (C), Akt (D), type I collagen (E), osterix (F), TGF- $\beta 1$ (G), HIF-1 (H), RUNX-2 (I) in hFOB cells under hypoxia-reoxygenation demonstrated by western blot analysis (A) and densitometry. *P $<0.05$ as compared with the control group.

BMP-2 and TGF- $\beta 1$ play a crucial role in inducing osteoblast differentiation and bone formation at the preosteoblast stage [10,11, 12]. Osteocalcin is an important marker of mature osteoblasts. The protein is shown to play a role in the differentiation of osteoblast progenitor cells, with significant up-regulation observed in both matrix synthesis and mineralization $[13,14]$. Several studies have demonstrated that Akt-related signalling pathways are involved osteoblast differentiation. Furthermore, Akt suppresses osteoblast apoptosis [15]. Type I collagen is the major component of the extra-cellular matrix in bone and plays an important role in cell adhesion, proliferation and differentiation of the osteoblast $[13,16]$. Osterix has been identified as a transcription factor that acts in the regulation of important osteoblast genes including osteocalcin, type I collagen and osteopontin [17]. Runt-related transcription factor 2 (RUNX2) is considered to be the major controlling transcription factor in osteoblast differentiation [18]. The hypoxia-inducible factor-1 (HIF-1) pathway is the central regulator of adaptive responses to low oxygen availability and is required for normal skeletal development [19]. The present study showed that remifentanil pretreatment has positive effects on the synthesis of
BMP-2, osteocalcin, Akt, type I collagen, osterix, TGF- $\beta 1$, HIF- $1 \alpha$, and RUNX2. This is the first observation of effects of remifentanil on factors associated with the proliferation and differentiation of osteoblasts under hypoxia-reoxygenation conditions.

Perez et al. demonstrated that cells of a human osteoblast-like cell line and MG63 express the three types of opioid receptors (mu, delta, and kappa)[20]. The effect of opioids on osteoblast proliferation has already been examined in previous studies. Inhibitory effects were observed in cells from human cancellous bone samples [21], while an increase in proliferation occurred in immortalized rat calvaria-derived cells [22]. In this study, remifentanil pretreatment followed by hypoxia-reoxygenation promoted osteoblast proliferation. The explanation of this difference can be that the remifentanil and a stress condition such as hypoxia-reoxygenation were not used in previous studies. We also demonstrated that the protective effect of remifentanil on proliferation, maturation and differentiation of osteoblasts was not blocked by naloxone. This result suggests that an opioid-receptor signalling does not mediate this effect. The effects of opioids in reducing ischemia-reperfusion injury have already been examined in nerve and myocardial cells 
$[23,24,25]$.

Remifentanil has unique pharmacokinetic advantages over other opioids, such as morphine and fentanyl, as it can be given perioperatively at very high doses without complications, such as ventilatory depression and prolonged sedation [26]. Although remifentanil is predominantly a mu agonist, its preconditioning effect has been studied most extensively in cells from heart tissue, which have mu, delta and kappa opioid receptors [27, 28]. In a septic mouse model, the protective effect of remifentanil against sepsis has also been demonstrated and found to be associated with the inhibition of inflammatory response and reactive oxygen species generation [7].

In this study, we document that remifentanil pretreatment has a beneficial influence on osteoblasts under hypoxia-reoxygenation conditions. Since hypoxia-reoxygenation induced cell damage in vitro usually reflects ischemia-reperfusion injury in vivo $[29,30]$, these findings suggest that remifentanil could reduce ischemia-reperfusion injury during the bone healing process. However, these positive effects were observed in osteoblasts, so in vivo and clinical trials would be needed to establish whether there is a viable therapeutic role for remifentanil.

\section{Conclusion}

This study shows that remifentanil pretreatment increases the osteoblast proliferation rate and stimulates the expression of BMP-2, osteocalcin, Akt, type I collagen, osterix, TGF- $\beta 1$, HIF- $1 \alpha$, and RUNX-2, which are associated with the proliferation and differentiation of osteoblasts in hypoxia-reoxygenation injury. No functional studies were performed to investigate the effects of remifentanil on the bone healing process. Therefore, although the findings of this study are limited to an in vitro interpretation, we suggest that remifentanil may have a beneficial effect in the recovery from bone stress injury.

\section{Acknowledgements}

This study was supported by Biomedical Research Institute Grant (2011-14), Pusan National University Hospital.

\section{Competing Interests}

The authors have declared that no competing interest exists.

\section{References}

1. Levinson RM, Shure D, Moser KM. Reperfusion pulmonary edema after pulmonary artery thromboendarterectomy. Am Rev Respir Dis. 1986; 134: 1241-1245.

2. McCord JM. Oxygen-derived free radicals in postischemic tissue injury. N Engl J Med. 1985; 312: 159-163.

3. Robin ED and Theodore J. Are there ischemic lung diseases? Arch Intern Med. 1982; 142: 1791-1793.
4. Watkins MT, Haudenschild CC, al-Badawi H, et al. Immediate responses of endothelial cells to hypoxia and reoxygenation: an in vitro model of cellular dysfunction. Am J Physiol. 1995; 268: H749-758.

5. Bolcal C, Yildirim V, Doganci S, et al. Protective effects of antioxidant medications on limb ischemia reperfusion injury. J Surg Res. 2007; 139: 274-279.

6. Gasbarrini A, Grigolo B, Serra M, et al. Generation of free radicals during anoxia and reoxygenation in perfused osteoblastlike cells. Clin Orthop Relat Res. 1997; (338): 247-252

7. Zongze Z, Jia Z, Chang C, et al. Protective effects of remifentanil on septic mice. Mol Biol Rep. 2010; 37: 2803-2808.

8. Wong GT, Huang Z, Ji S, et al. Remifentanil reduces the release of biochemical markers of myocardial damage after coronary artery bypass surgery: a randomized trial. J Cardiothorac Vasc Anesth. 2010; 24: 790-796.

9. Gerstenfeld LC, Thiede M, Seibert K, et al. Differential inhibition of fracture healing by non-selective and cyclooxygenase- 2 selective non-steroidal anti-inflammatory drugs. J Orthop Res. 2003; 21: 670-675.

10. Chen D, Zhao M, Mundy GR. Bone morphogenetic proteins. Growth Factors. 2004; 22: 233-241.

11. Li X and Cao X. BMP signaling and skeletogenesis. Ann N Y Acad Sci. 2006; 1068: 26-40.

12. Noda $\mathrm{M}$ and Camilliere JJ. In vivo stimulation of bone formation by transforming growth factor-beta. Endocrinology. 1989; 124: 2991-2994.

13. Pavlin D, Zadro R, Gluhak-Heinrich J. Temporal pattern of stimulation of osteoblast-associated genes during mechanically-induced osteogenesis in vivo: early responses of osteocalcin and type I collagen. Connect Tissue Res. 2001; 42: 135-148.

14. Ryoo HM, Hoffmann HM, Beumer T, et al. Stage-specific expression of Dlx-5 during osteoblast differentiation: involvement in regulation of osteocalcin gene expression. Mol Endocrinol. 1997; 11: 1681-1694.

15. Ghosh-Choudhury N, Abboud SL, Nishimura R, et al. Requirement of BMP-2-induced phosphatidylinositol 3-kinase and Akt serine/threonine kinase in osteoblast differentiation and Smad-dependent BMP-2 gene transcription. J Biol Chem. 2002; 277: 33361-33368.

16. Jagodzinski M, Drescher $\mathrm{M}$, Zeichen J, et al. Effects of cyclic longitudinal mechanical strain and dexamethasone on osteogenic differentiation of human bone marrow stromal cells. Eur Cell Mater. 2004; 7: 35, 41; discussion 41.

17. Ducy P, Desbois C, Boyce B, et al. Increased bone formation in osteocalcin-deficient mice. Nature. 1996; 382: 448-452.

18. Komori T. Regulation of osteoblast differentiation by transcription factors. J Cell Biochem. 2006; 99: 1233-1239.

19. Wang Y, Wan C, Deng L, et al. The hypoxia-inducible factor alpha pathway couples angiogenesis to osteogenesis during skeletal development. J Clin Invest. 2007; 117: 1616-1626.

20. Perez-Castrillon JL, Olmos JM, Gomez JJ, et al. Expression of opioid receptors in osteoblast-like MG-63 cells, and effects of different opioid agonists on alkaline phosphatase and osteocalcin secretion by these cells. Neuroendocrinology. 2000; 72: 187-194.

21. Elhassan AM, Lindgren JU, Hultenby K, et al. Methionine-enkephalin in bone and joint tissues. J Bone Miner Res. 1998; 13: 88-95.

22. Rosen H, Krichevsky A, Bar-Shavit Z. The enkephalinergic osteoblast. J Bone Miner Res. 1998; 13: 1515-1520.

23. Kato R and Foex P. Myocardial protection by anesthetic agents against ischemia-reperfusion injury: an update for anesthesiologists. Can J Anaesth. 2002; 49: 777-791.

24. Charron C, Messier C, Plamondon H. Neuroprotection and functional recovery conferred by administration of kappa- and delta 1-opioid agonists in a rat model of global ischemia. Physiol Behav. 2008; 93: 502-511.

25. Warltier DC, Pagel PS, Kersten JR. Approaches to the prevention of perioperative myocardial ischemia. Anesthesiology. 2000; 92: 253-259.

26. Servin FS and Billard V. Remifentanil and other opioids. Handb Exp Pharmacol. 2008; (182): 283-311.

27. Zhang Y, Irwin MG, Wong TM. Remifentanil preconditioning protects against ischemic injury in the intact rat heart. Anesthesiology. 2004; 101: 918-923.

28. Yu CK, Li YH, Wong GT, et al. Remifentanil preconditioning confers delayed cardioprotection in the rat. Br J Anaesth. 2007; 99: 632-638.

29. Li C and Jackson RM. Reactive species mechanisms of cellular hypoxia-reoxygenation injury. Am J Physiol Cell Physiol. 2002; 282: C227-241.

30. Terui K, Enosawa S, Haga S, et al. Stat3 confers resistance against hypoxia/reoxygenation-induced oxidative injury in hepatocytes through upregulation of Mn-SOD. J Hepatol. 2004; 41: 957-965. 